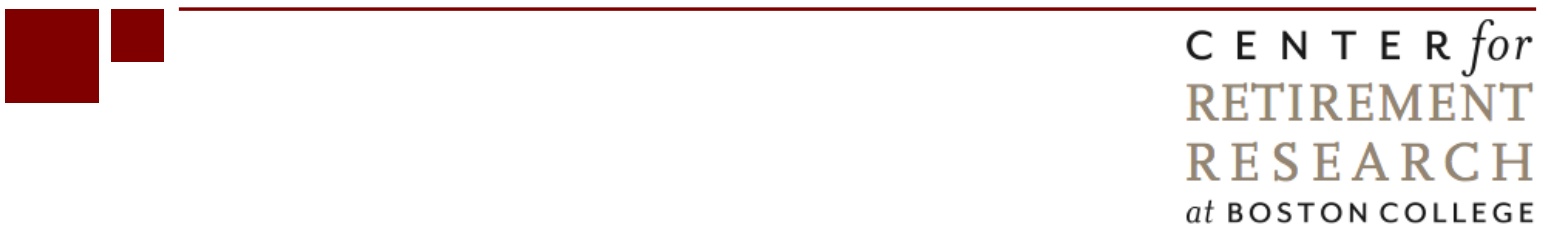

\title{
THE IMPACT OF TEMPORARY ASSISTANCE PROGRAMS ON DISABILITY ROLLS AND RE-EMPLOYMENT
}

\author{
Stephan Lindner and Austin Nichols
}

CRR WP 2012-2

Date Released: January 2012

Date Submitted: January 2012

\author{
Center for Retirement Research at Boston College \\ Hovey House \\ 140 Commonwealth Avenue \\ Chestnut Hill, MA 02467 \\ Tel: 617-552-1762 Fax: 617-552-0191 \\ http://crr.bc.edu
}

Stephan Lindner is a research associate at the Urban Institute. Austin Nichols is a senior research associate at the Urban Institute. The research reported herein was pursuant to a grant from the U.S. Social Security Administration (SSA) funded as part of the Retirement Research Consortium (RRC). The findings and conclusions expressed are solely those of the authors and do not represent the opinions or policy of SSA, any agency of the federal government, the RRC, the Urban Institute, or Boston College. The authors would like to thank Pamela Loprest for helpful comments and Thomas Callan for excellent research assistance.

(C) 2012, by Stephan Lindner and Austin Nichols. All rights reserved. Short sections of text, not to exceed two paragraphs, may be quoted without explicit permission provided that full credit, including (C) notice, is given to the source. 


\title{
About the Center for Retirement Research
}

The Center for Retirement Research at Boston College, part of a consortium that includes parallel centers at the University of Michigan and the National Bureau of Economic Research, was established in 1998 through a grant from the Social Security Administration. The Center's mission is to produce first-class research and forge a strong link between the academic community and decision-makers in the public and private sectors around an issue of critical importance to the nation's future. To achieve this mission, the Center sponsors a wide variety of research projects, transmits new findings to a broad audience, trains new scholars, and broadens access to valuable data sources.

\author{
Center for Retirement Research at Boston College \\ Hovey House \\ 140 Commonwealth Avenue \\ Chestnut Hill, MA 02467 \\ phone: 617-552-1762 fax: 617-552-0191 \\ e-mail: crr@bc.edu \\ crr.bc.edu
}

\author{
Affiliated Institutions: \\ The Brookings Institution \\ Massachusetts Institute of Technology \\ Syracuse University \\ Urban Institute
}




\begin{abstract}
Workers who lose their job draw from temporary assistance programs in order to buffer their income losses. They are also more likely to apply for Disability Insurance (DI) and Supplemental Security Income (SSI). Whether participating in temporary assistance programs influences the application decision for DI and SSI, however, is largely unknown. We address this question using panels from the Survey of Income and Program Participation (SIPP) matched to administrative records on DI and SSI applications. We distinguish between four temporary insurance programs: Temporary Assistance for Needy Families (TANF), Supplemental Nutrition Assistance Program (SNAP), Unemployment Insurance (UI), and Temporary Disability Insurance programs (TDI). For each of these programs, we construct instruments based on state policies in order to address endogeneity concerns. Our results indicate that workers select into temporary assistance and disability programs by income and health status. When controlling for selection bias, we find evidence that increased access to UI benefits reduces applications for DI, while increased access to SNAP benefits increases applications for SSI. These results suggests that (i) applications for DI and SSI are sensitive to participation in temporary assistance programs; (ii) the strength of the net effect depends on the overlap between target populations; and (iii) the direction of the net effect depends on benefit levels or on institutional and population characteristics.
\end{abstract}

\title{
Policy abstract
}

Workers who lose their jobs can draw from temporary assistance programs, apply for Disability Insurance (DI) and Supplemental Security Income (SSI), or both. Whether participating in temporary assistance programs influences the application decision for DI and SSI is an important open question, which we address using the Survey of Income and Program Participation matched to administrative records on DI and SSI applications. We distinguish four programs: Temporary Assistance for Needy Families (TANF), Supplemental Nutrition Assistance Program (SNAP), Unemployment Insurance (UI), and Temporary Disability Insurance programs (TDI). We estimate the observed association between three outcomes after a job loss (re-employment, application for DI, and application for SSI) and participation in each of the four temporary assistance programs. Our results show that job losers are less likely to be reemployed if they participate in any of the four temporary assistance programs, that UI 
recipients are less likely to apply for SSI, TDI recipients are more likely to apply for DI, and SNAP participants are less likely to apply for DI and more likely to apply for SSI. Since associations are biased by selection into participation, we use state-level policy as exogenous variation to identify the causal effect of participation on the three outcomes. Our results suggest that expansions of UI reduce applications for DI, but expansions of SNAP may increase applications for SSI. Participation in assistance programs seems to influence applications for DI and SSI, but the strength and direction of the net effect depends on specific characteristics of the programs. 


\section{Introduction}

Applications for Social Security Disability Insurance (DI) and for Supplemental Security Income (SSI) are high during periods of high unemployment (Bound and Burkhauser 1999, Black, Daniel and Sanders 2002, Rupp and Stapleton 1995, Autor and Duggan 2006). This correlation has been interpreted as evidence that workers tend to move onto DI after having lost their job. Consistent with this view are findings that applicants for DI (and to lesser extent, for SSI) experience large income losses around the time of application, some of which they can buffer by receiving temporary assistance (Bound, Burkhauser and Nichols 2003). Whether these payments influence application decisions for DI and SSI, however, is largely unknown.

The goal of this study is to examine how program participation in four temporary assistance programs affects claims for DI and SSI of adults who recently stopped working. These programs are Temporary Assistance for Needy Families (TANF), Supplemental Nutrition Assistance Program (SNAP), Unemployment Insurance (UI), and Temporary Disability Insurance programs (TDI). We analyze how participation in these programs affects claims for DI and SSI both directly through applications and indirectly through re-employment, as employed workers are less likely to claim DI or SSI benefits.

We first discuss several channels through which participation in one of the temporary assistance programs may affect re-employment and application for DI or SSI. Cash benefits from such temporary assistance programs could increase or decrease applications for DI or SSI, depending on whether such transfers support workers in their application for DI and SSI or whether they reduce the need to apply for DI and SSI in order to receive additional income support. Similarly, temporary cash benefits make searching for a job less worthwhile, but also may make it possible to engage in job search in the first place. The net effect of participating in a temporary assistance program on re-employment and on applications for DI and SSI is therefore theoretically ambiguous.

We select a sample of workers who have lost their job and create spells of non-employment ending in re-employment, application for DI, or application for SSI. Since OLS estimates are likely to be biased due to selection and simultaneity, we construct instruments based on state policies and rules for each of the temporary assistance programs.

Our OLS estimates show that participation in each of the four temporary assistance programs is associated with a lower re-employment probability. Furthermore, UI claimants tend 
not to apply for SSI, while TDI recipients tend to apply for DI. Workers who are more likely to receive SNAP benefits are also more likely to apply for SSI, but less likely to apply for DI. These results could signify causal effects of participating in temporary assistance programs on re-employment and applications for DI and SSI, but they are also consistent with selection by income and health status. The selection hypothesis can explain the observed associations even if there is no net casual effect of participation on applications and re-employment. For example, if low potential income and poor health cause both higher rates of participation in SNAP and application for SSI, then expansions of SNAP need not increase applications for SSI.

Results from IV regressions are in most cases quite different. For re-employment, we do not find that participation in temporary assistance programs leads to a lower re-employment probability. Furthermore, participation in UI decreases applications for DI, which is consistent with the idea that this program is a substitute for DI. For SSI, we find a positive effect of taking up SNAP benefits on subsequent applications, but only for the specification which uses months instead of spells as the unit of observation.

Overall, these results show that applications for DI and SSI are sensitive to participation in temporary assistance programs, at least for workers who find themselves without a job. This finding is similar to results from recent studies for UI (Lindner 2011, Rutledge 2011), and contradicts the notion that application decisions are solely driven by long-term income considerations.

These results also show that not all temporary assistance programs influence disability insurance applications, on net and on average. Only the two largest temporary assistance programs, UI and SNAP, have a discernible effect, namely on applications for DI and SSI, respectively. UI participation does not influence applications for SSI and SNAP participation does not influence applications for DI, which suggests that the overlap in target populations matters as well. SNAP and SSI are means-tested programs targeting poor households. UI and DI are not means-tested programs, but workers must have a recent and substantial work history in order to qualify for these programs.

Finally, the negative effect of UI participation on applications for DI but the positive effect of SNAP participation on applications for SSI suggests that participation in temporary assistance programs can influence applications for DI and SSI in different ways. We discuss several reasons why such a heterogeneous effect may occur: the effect of receiving benefits could depend on the 
benefit amount; population characteristics could influence how receiving benefits affects applications for DI and SSI; and other program characteristics could also play a role.

The following section provides an overview of the different programs. We then discuss the primary channels through with participation in temporary assistance programs may affect applications for DI and SSI. Sections 4 to 6 describe the econometric approach, data and sample selection, and the main findings. The last section provides a discussion of the results and some concluding remarks.

\section{Overview of Temporary Assistance and Disability Programs}

In this section, institutional parameters of the temporary assistance programs and DI and SSI are described. Given the complexity of these programs, we focus on rules and regulations that are relevant for this study. ${ }^{1}$

1. Social Security Disability Insurance (DI) and Supplemental Security Income for the blind and disabled (SSI)

DI was enacted in 1956 to insure workers and their dependents against loss of earnings and higher health care expenses due to permanent disability by providing monetary benefits and access to Medicare. In 1974, SSI was added as a second program. Medical eligibility criteria and the application determination process are the same for both insurance programs, but their nonmedical eligibility criteria are different. Specifically, DI is an insurance for workers with a recent and relatively steady work history in covered work while SSI is a means-tested program for people with income and assets below certain limits (for assets, the limit is $\$ 2000$ for individuals and $\$ 3000$ for couples). Individuals can apply for both programs if they meet all respective nonmedical requirements.

Applicants either need to have a specific disabling condition or need to show that they cannot perform their previous work and any other type of work. Less than 40 percent of initial applications are accepted, and many of these are for categorically eligible conditions, such as blindness. One-third of all denied applicants file an appeal. The majority of such appeals are

\footnotetext{
${ }^{1}$ Information in this section comes from (U.S. Committee on Ways and Means 1996, U.S. Committee on Ways and Means 2000, U.S. Committee on Ways and Means 2004), Comparison of State UI Laws and Significant Provisions of State UI Laws (http://www.ows.doleta.gov/unemploy/comparison2011.asp), (Rowe, Murphy and Mon 2010), (Social Security Administration 1997),
} 
successful, but the appeal process often takes many months or even years. A successful application can result in a substantial one-time payment of retroactive benefits, so that applicants who have applied but who might otherwise return to work (were there no accumulated potential benefit on the line) might persist in a long appeals process in order to maintain the option value of retroactive benefits.

DI benefits are calculated in the same way as retirement benefits. After calculating the Average Indexed Monthly Earnings (AIME) from past earnings, a piecewise linear formula is applied to obtain DI benefits, which are also called Principal Insurance Amounts (PIA). The PIA is a concave function of past earnings, i.e., workers with low past earnings are reimbursed a higher fraction of their past earnings than workers with high past earnings. DI benefits are substantial: in 2008, DI benefits for the average wage earner were $\$ 1500$ per month, or about 40 percent of earnings. In addition, beneficiaries are also eligible for Medicare two years after disability onset.

Benefits for SSI are lower and not tied to past earnings. The maximum amount in 2008 was $\$ 637$ per month for an individual. Since SSI is a means-tested program, other income sources are counted against these benefits. Specifically, unearned income including UI and DI benefits reduce SSI benefits dollar-for-dollar after a general deduction of $\$ 20$. One dollar of earned income decreases SSI benefits by half a dollar after an earned-income deduction of $\$ 65$. Besides cash transfers, beneficiaries also receive Medicaid in most states. ${ }^{2}$

\section{Unemployment Insurance}

The unemployment insurance system was established as part of the Social Security Act of 1935. It is a federal-state partnership aimed at providing short-term cash benefits to individuals who lose or quit their job through no fault of their own. Unemployed workers are eligible for UI benefits if they fulfill all monetary and non-monetary requirements. Monetary entitlement requires sufficiently high wage earnings during the base period, which is the first four of the last five completed calendar quarters before the worker files a claim. States typically compare the quarter with the highest earnings to a threshold, and sometimes also have thresholds for the two

\footnotetext{
${ }^{2}$ Most states grant Medicaid to SSI beneficiaries automatically. Some states, however, apply their Medicaid eligibility criteria to SSI beneficiaries who then do not necessarily qualify for these benefits.
} 
highest quarters or the whole base period. Furthermore, the majority of states require claimants to have earned wages during at least two of the four base period quarters.

Non-monetary eligibility criteria concern both the reason of job separation and ongoing claims. Workers must have lost their job through no fault of their own, i.e. either involuntarily, or voluntarily but with a good cause (e.g. due to illness). Workers must also show that they are able and available to work. Most states consider filing a claim and registering for work at a public employment office as sufficient evidence that the worker is able to work. Regarding availability to work, states require workers to be either available for any kind of work, for suitable work (i.e., work previously done), or for work in the worker's usual occupation. Finally, some states also require evidence that UI recipients actively seek work, for instance by documenting job applications.

Formulas for weekly UI benefits specify a minimum and a maximum benefit amount as well as a percentage within these boundaries. The percentage is typically 1/26 to 1/23 of either earnings in the highest earnings quarter or of average earnings in the two highest earnings quarters. A quarter has 13 weeks, so UI benefits replace about half of the earnings in the highest or two highest quarters within the minimum and maximum amounts. These amounts vary considerably across states. For instance, Massachusetts had the highest maximum benefit amount with \$639 per month last year, while Mississippi had the lowest one with \$235 per month.

The American Recovery and Reinvestment Act (ARRA) provided financial incentives for states to adopt specific UI “modernization” provisions. These include Alternative Base Periods $(\mathrm{ABP})^{3}$ of earnings histories used for calculation of eligibility and benefits, UI eligibility while seeking only part-time work, UI eligibility after job separation due to compelling family reasons or harassment, continuation of UI benefits after regular benefits are exhausted while in approved training, and dependent's allowances. A number of states already had such provisions, but since 2009, more states have adopted some of these provisions and thereby enlarged the pool of unemployed workers eligible for UI.

\footnotetext{
${ }^{3}$ The alternative base period is either the last four completed quarters or the last four quarters, including the (not completed) quarter during which benefits are filed.
} 


\section{Supplemental Nutrition Assistance Program (SNAP)}

The Supplemental Nutrition Assistance Program (SNAP), also known as food stamps, is a means-tested program for poor households. Established with the Food Stamp Act in 1964, the program currently serves more than 40 million Americans, or more than 12 percent of the population.

Households qualify for SNAP if their gross (or basic) household income does not exceed 130 percent of the federal poverty line and if their net monthly household income does not exceed 100 percent of the federal poverty line. Monthly gross household income is calculated by summing up income of all household members. SSI and DI benefits are part of gross household income. Net (or counted) household income is obtained from gross household income by adjusting for family size, child support payments, and shelter expenses. Liquid assets also cannot exceed eligibility limits, which are currently $\$ 2000$ for households with no elderly or disabled member and $\$ 3000$ for households with elderly or disabled members. ${ }^{4}$

Benefits are calculated by subtracting 30 percent of net household income from the maximum benefit amount, which depends on the size of the household. For instance, the maximum monthly benefit amount of a four-person household was $\$ 668$ in 2010. If such a household has a net income of $\$ 900$ per month, then SNAP benefits would be $\$ 398$ per month (\$668 - $0.3 \times$ x \$900). If the same household has a net income of $\$ 1800$, then SNAP benefits would only be $\$ 128$ per month. Since SSI or DI benefits are included in household income, receiving these cash transfers reduces the amount of SNAP benefits a household receives.

SNAP benefits are tied to work requirements. Able-bodied household members between the ages of 16 and 59 must fulfill work, search, and training requirements i.e. they must seek work, accept a suitable job offer if received, and are not allowed to reduce work effort below 30 hours a week or to quit a job without a good cause. ${ }^{5}$ Households with no dependents are also ineligible for SNAP if they received benefits for three months during the last three years while not working for at least 20 hours a week or not participating in a training program.

\footnotetext{
${ }^{4}$ Liquid assets include checking and savings accounts, stocks and bond, individual retirement accounts, and nonrecurring lump-sum payments such as insurance settlements. Non-liquid assets are personal and residential property or life insurance policies and pension plans.

${ }^{5}$ If these work requirements are not met, then a household is disqualified for some time, which depends on state rules and whether a violation was the first, second, or third one.
} 


\section{Temporary Assistance for Needy Families}

Temporary Assistance for Needy Families (TANF) is the successor to Aid to Families with Dependent Children (AFDC), established in 1935 to provide income support for poor families. In 1996, AFDC was replaced by TANF. Both are means-tested programs, providing benefits only to families with resources under set limits. TANF increased focus on promoting work and decreasing dependency among poor families. It does this in a number of ways including requiring activities that lead to or prepare for work, limiting the number of months a family can receive benefits, and allowing working families to keep a greater portion of benefits (called earned income disregards). Its block grant structure also provides additional flexibility to states to structure the program within federal guidelines and requirements.

States set income and asset limits as well as benefit levels. While states have different eligibility rules, they share the same basic criteria. A family must have a child younger than 18 years $^{6}$; if two parents are present, then some states require a minimum work history. Families which meet these requirements need to pass an income and asset test. Family income generally includes all earnings, but states differ substantially in their treatment of unearned income. A family's gross income is then compared to an income standard set by the state. Furthermore, some states also compute family net income by subtracting certain earnings disregards from gross earned income and then comparing the net income to the respective income standard.

There is substantial difference in income standards by states. For instance, in 2009 a family of three could earn as little as \$269 per month in Alabama and as much as \$1802 per month in Hawaii and still be eligible for TANF. Asset limits are typically in the range of $\$ 2000$ to $\$ 3000$. Benefits are generally calculated by subtracting families' net income from a so-called payment standard, which is set by the states and varies by family size. All but two states also disregard a portion of earnings before computing benefits. Benefits vary considerably by states. For instance, the maximum monthly benefit amount for a family of three was between \$170 in Mississippi and $\$ 923$ in Alaska. In order to remain eligible, families must also engage in work-related activities. These also vary greatly by states in terms of who must work, how much work is required, and what activities are considered as work. Beneficiaries also become automatically eligible for Medicaid.

\footnotetext{
${ }^{6}$ In some states, pregnant women are eligible as well.
} 
TANF and SNAP are closely related. States administer both programs, often in the same office. While SNAP is a federal program, states can nevertheless apply some TANF rules for SNAP claimants as well. It is then not surprising that many TANF recipients also receive SNAP benefits. We will return to this point later in the empirical discussion.

\section{Temporary Disability Insurance}

Temporary disability insurance (TDI) is either provided by employers or by the state. Only five states currently administer a temporary disability insurance program. The first state to introduce one was Rhode Island in 1942, followed by California (1946), New Jersey (1948), New York (1949) and Hawaii (1969).

In order to qualify for benefits, a worker needs to have sufficient past employment or earnings (depending on state laws) and must not be able to perform regular or customary work because of a physical or mental illness. In all states, a claimant cannot receive UI and TDI at the same time. Benefits are calculated similarly to UI benefits but tend to be more generous. They typically replace about half of the earnings in the base period or highest wage quarter between the minimum and maximum amounts. For California, minimum and maximum weekly benefits in 2010 were $\$ 50$ and $\$ 987$, respectively, while UI benefits were in the range of $\$ 40$ to $\$ 450$ per week. Benefits are paid for 26 to 52 weeks.

\section{Theoretical framework}

Conceptually, receiving cash benefits through temporary assistance programs may influence re-employment and applications for DI and SSI through both a substitution and an income channel.

With regard to re-employment, a substitution effect exists because cash benefits from temporary assistance programs are reduced or terminated if a person starts working again. For instance, UI benefits are only paid while a person is not working. Similarly, a one dollar increase in earnings reduces SNAP benefits by 30 cents. The substitution effect leads to workers remaining unemployed for a longer time, which in turn can decrease the probability of finding a 
new job. For UI, studies have generally found that receiving UI benefits increases unemployment duration (Meyer 1990; Card, Chetty and Weber 2007). ${ }^{7}$

With regard to applications for DI and SSI, receiving temporary assistance benefits directly reduces SSI benefits and therefore the value of applying for the program. For DI, benefits are not reduced by other transfer income, but a substitution effect nevertheless exists, because the value of applying for DI benefits is reduced if higher amounts of other income are available, and the application process itself is far from costless. Intuitively, receiving DI is less desirable if one already receives $\$ 10000$ per month as compared to $\$ 100$ per month. ${ }^{8}$ However, if a longer time out of work because of temporary income support results in "scarring", i.e. worsening of health and loss of human capital, then receiving temporary assistance can also make applying for DI or SSI more attractive.

Receiving temporary assistance can also have an income effect. For re-employment, a higher income can enable individuals out of work to engage in job search activities, which increases their chance of finding a new job. For instance, Young (2011) finds that UI benefits increase search effort, especially among low-wage unemployed workers. With respect to DI or SSI, other income might provide crucial support during applications, but it could also help stabilize health. Therefore, the income effect of participating in one of the temporary assistance programs increases the probability of re-employment, but may increase or decrease the probability of applying for DI or SSI. Overall, the net effect of program participation on applications for DI or SSI and on re-employment is ambiguous.

Temporary assistance programs do not only give out cash assistance, they also provide incentives and assistance for beneficiaries to find work. These program features, if effective, increase the chances of becoming re-employed. However, they may also have unintended consequences insofar as individuals faced with these requirements may look for other programs such as DI or SSI where they can avoid such requirements. Other features of the programs make them institutional complements or substitutes to DI and SSI. For instance, SNAP caseworkers might encourage clients to apply for SSI since it has similar income eligibility criteria.

\footnotetext{
${ }^{7}$ Longer unemployment duration due to higher UI benefits may also be attributed to a liquidity effect: higher UI benefits relax credit constraints, which in turns allow workers to search longer for jobs (Chetty 2008).

${ }^{8}$ More precisely, the net value of applying for DI or SSI decreases with other income if the utility function is strictly concave.
} 
The discussion so far assumes that workers are assigned randomly to a temporary assistance program. However, workers decide to apply for a temporary assistance program based on characteristics such as age, health, business conditions, or attitudes toward receiving cash transfers. Some of these characteristics are observed, but not all of them. This poses a problem if unobserved characteristics which influence temporary assistance take-up also influence job search and applications for DI and SSI. In that case, comparing program participants with nonparticipants based on observable characteristics alone is problematic, since it confounds treatment effects with selection effects based on unobserved characteristics. Moreover, the decision to search hard for a job or to apply for DI or SSI may also influence whether or not to claim temporary assistance. Such simultaneous decisions make it hard to identify the causal effect of receiving temporary assistance benefits as well. The following section explains how we empirically address these issues of selection and reverse causality.

\section{Empirical Approach}

We propose to estimate whether non-employed workers' participation in a temporary assistance program affects their probability of becoming re-employed, applying for DI, or applying for SSI. The basic econometric model may be stated as followed:

$$
y_{i d}=\beta_{0 d}+\beta_{1} U I_{i s}+\beta_{2} T D I_{i s}+\beta_{3} T A N F_{i s}+\beta_{4} S N A P_{i s}+\gamma X_{i d}+\varepsilon_{i d},
$$

where $y_{i d}$ denotes the respective outcome of individual $i$ who has been non-employed for $d$ months, $\beta_{0 d}$ is a month-specific intercept (specified as a linear time trend) if individual-month is the unit of observation, $U I_{i s}, T D I_{i s}, T A N F_{i s}$, and $S N A P_{i s}$ are dummy variables for participation in one of the four programs during a spell $s, X_{i d}$ is a vector of demographic characteristics and the unemployment rate, and $\varepsilon_{i d}$ is an individual-month specific error term (capturing baseline hazards). ${ }^{9}$

Equation (13) uses months as unit of observation, which is a natural specification given the monthly longitudinal data used in this study. However, it is also plausible to use spells as unit of observation:

\footnotetext{
${ }^{9}$ Specifically, demographic variables: age, age squared, sex, race (white and not Hispanic, black, Native American, and Hispanic), marital status, high-school diploma, some college, number of children under 18 years, Medicaid coverage, health insurance coverage, last year's earnings, work limitation, log of duration of the non-employment spell, the unemployment rate, and dummy variables for calendar years and months.
} 


$$
y_{i s}=\beta_{0}+\beta_{1} U I_{i s}+\beta_{2} T D I_{i s}+\beta_{3} T A N F_{i s}+\beta_{4} S N A P_{i s}+\gamma X_{i s}+\varepsilon_{i s} .
$$

In what follows, we report estimates for both equations since they both are legitimate ways to measure the effect of temporary assistance participation on re-employment and applications for DI and SSI. ${ }^{10}$

For both specifications, estimates are only consistent if the error term is uncorrelated with temporary assistance participation. However, this assumption is likely to be violated for two reasons, simultaneous equations bias and omitted variable bias.

An omitted variable bias exists if variables that are correlated with participation in a temporary assistance program and that are also correlated with the outcome variable are not included in the regression. For instance, individuals with unobserved health problems are more likely to receive TDI benefits and to apply for DI or SSI. Past labor force participation could also be such a confounding variable, if people with weak labor force attachment are more likely to qualify for TANF or SNAP as well as SSI. Furthermore, aggregate-level variables such as business conditions may contribute to correlated participation in temporary assistance programs, DI and SSI applications, and re-employment.

A simultaneous equation bias occurs if an outcome influences participation in a temporary assistance program. For instance, an individual who is very likely to become re-employed in the near future might not bother applying for UI or other cash assistance. Similarly, a person who plans to apply for DI might find it to be too much work to first claim other benefits. In such cases, OLS would be biased towards a negative value.

In order to address these issues, we instrument participation in temporary assistance programs. The first-stage regressions for participation in one of the temporary assistance programs may be written as follows:

$$
T A_{i s p}=\alpha_{0}+\varphi Z_{i s}+\delta X_{i s}+\mu_{i s p}
$$

where $T A_{i s}$ measures program participation in one of the four programs $p, Z_{i s}$ are instruments which are included in this equation, but not in equation (1) or (1'), $X_{i s}$ are exogenous variables

\footnotetext{
${ }^{10}$ We also estimated equation (1) using monthly dummies for temporary assistance participation. The results are qualitatively the same as the ones we find for equation (1) and are therefore not reported here.
} 
included in both equations, and $\mu_{i s}$ is an error term. There is one first-stage equation for each of the four programs.

Proper instruments need to satisfy two requirements: being correlated with temporary assistance participation (instrument relevance) and affecting outcomes only through participation in the temporary assistance program (exclusion restriction). Regarding the first requirement, even if instruments are relevant, they might be weak. In that case, IV estimates may be inconsistent and imprecisely measured. As an indicator for weak instruments, we report the Kleibergen-Paap Wald F statistic, which tests that all instruments are uncorrelated with program participation and which is a generalization of the F-statistic for more than one endogenous variable and non-i.i.d. error terms (Staiger and Stock 1997).

If instruments also fulfill the monotonicity assumption ${ }^{11}$, then it has been shown for the case of one endogenous and one instrumental variable that the IV estimator identifies the local average treatment effect (LATE), which is the average treatment effect for those who are induced to participate in a program because of variation in the instrument (Imbens and Angrist 1994). As mentioned in the theoretical framework, this treatment effect could capture the effect of receiving cash transfers on outcomes, which could depend on the population involved, or it could identify the effect of other program characteristics. The LATE can be thought of as the effect on mean outcomes of manipulating the excluded instrument (program parameters) and thereby inducing greater participation, a kind of marginal treatment effect.

Instruments used here include state policies and rules for the four temporary assistance programs. We do not include state fixed-effects since most of the cross-state variation would then vanish. Therefore, we have to assume that differences in policies across states are not correlated with other state-level characteristics that influence outcomes; otherwise, the exclusion restriction would be violated. This is not an implausible assumption since DI and SSI are administered by the federal government. However, state-level characteristics could both influence participation in temporary assistance programs and applications for DI and SSI. For instance, states with high UI or TANF benefits might have a population with a high valuation for social insurance programs. As a consequence, workers might be more inclined to apply for DI or SSI because of lower stigma.

\footnotetext{
${ }^{11}$ Monotonicity means that everyone who participates for one value of the instrument also participates for a different value of the instrument if on average more people participate under the latter value than under the former.
} 
We estimate equation (1) and (1') for each of the three outcomes separately, both as OLS and as IV regressions. Separate estimation of the different outcomes assumes that, conditional on observables, the occurrence of each outcome is independent from the others. While this is not an innocuous assumption, we prefer this approach for computational simplicity over estimating all three outcomes simultaneously. Similarly, we focus on linear models even though non-linear models are more efficient. Aside from computational reasons associated with failures of convergence and the necessity of additional distributional assumptions, using linear models allows for a simple interpretation of IV results as local average treatment effects.

\section{Data and Sample Selection}

The primary data source is the Survey of Income and Program Participation (SIPP) for the years 1996 to 2010. The SIPP is a nationally representative sample of individuals 15 years of age and older of the civilian non-institutionalized population. People are interviewed once every four months, called a wave, for two to four years. When interviewed, respondents are asked to provide information about the preceding four months, called reference months. Connecting reference months of different waves generates panels of two to four years. We restrict out attention to the years from 1996 on, since we have better instruments for this time period, especially for SNAP.

In order to identify applications for DI and SSI, SIPP panels are matched to administrative records (the 831 records) from the Social Security Administration (SSA). An 831 record is opened whenever a person applies for DI or SSI, and subsequently tracks administrative actions on open applications. We use 831 records to identify the date of the first application and the type of application, where we distinguish between applications for DI and SSI. The latter group also contains concurrent applications, i.e. applications for both DI and SSI. ${ }^{12}$

The sample for this analysis includes workers who complete all interviews, are matched to Social Security data (either disclose their Social Security Number or have a match based on name, birth date, and address so that they can be matched to 831 files), and who experience a job loss. A job loss occurs when a person works all weeks during the previous month (including

\footnotetext{
${ }^{12}$ Alternatively, we could have distinguished between three groups of applicants, DI only, SSI only, and concurrent applications. We treat the last two groups as one category since few applications for SSI are observed in the sample and the results for concurrent applications are similar to the results for SSI only applications if regressions are estimated for each outcome separately.
} 
being absent from work), but does not work for at least one week during the current month. An individual remains non-employed after job loss until he or she finds a job or applies for DI or SSI. We disregard spells for which a worker is younger than 20 or older than 57 at the time of job loss. We chose age 57 as the highest age in order to ensure that all workers in the sample are younger than 62 throughout all spells and panels. In order to use prior earnings information, the sample is also restricted to individuals with an earnings history of more than three months prior to job loss. Layoffs are excluded as well as spells with missing interview waves or state information. ${ }^{13}$ The final sample contains 32,208 workers. Table 1 shows sample selection steps and corresponding sample sizes.

Respondents in the SIPP report the amount of income they receive from different types of programs. For UI and TDI, we simply consider an individual to be on one of these programs if he or she reports receiving cash income from it. For TANF, we use SIPP's relationship information within households to identify whether a child or its parents receive such benefits. Finally, an individual participates in SNAP if anyone in the household receives benefits from the program. We use several sources to construct instruments for participation in these programs. Appendix A describes these instruments in detail. For UI, "Significant Provisions of State UI Laws" and the “Comparison of State Unemployment Insurance Laws” from the Department of Labor contain detailed information about states' policies. ${ }^{14}$ These include the maximum UI benefit amount, whether states stipulate an initial waiting week where benefits are not paid, and whether UI claimants must have worked for at least two quarters during the base period.

Many states adopted certain monetary and non-monetary eligibility rules as part of the American Recovery and Reinvestment Act (ARRA). We construct variables indicating when states adopted these provisions. Some states had such provisions in place well before the ARRA was passed, and merely certified the effective dates of the policy. For these cases, we use the “Comparison of State Unemployment Laws” to determine when they adopted the provision. ${ }^{15}$

\footnotetext{
${ }^{13}$ Layoffs are job separations due to slack work, material shortage, or similar reasons. Workers who are affected by a layoff typically return to their employer and are therefore not interesting for this study.

${ }^{14}$ See http://www.ows.doleta.gov/unemploy/statelaws.asp\#sigprouilaws .

${ }^{15}$ Information for these provisions is currently only available to us for the years 2001 and later. We assume that states which had a provision in place in 2001 also have the provision in place in earlier years since UI laws are infrequently changed.
} 
Concerning TANF, benefits depend on states’ payment standards. We use benefit formulas to create TANF benefits at zero dollar earnings. These benefits best reflect transfers that potential recipients currently out of work may claim.

SNAP benefit rules are set by the federal government and therefore do not change across states. However, states administer the program and in this capacity have control over some of its aspects, especially with regards to eligibility. We use information from the SNAP Program Rules Database (Finegold, Margrabe and Ratcliffe 2010) to construct three sets of instruments; these instruments are also used in a study which examines the role of SNAP in reducing food insecurity (Ratcliffe and McKernan 2010). The instruments are: outreach spending per person, use of biometric information, and eligibility for noncitizens. For the latter, we distinguish between full eligibility (all noncitizens) and partial eligibility (only noncitizens who either have a disability, are under 18 years old, or have been U.S. residents for more than five years). Based on this state-level information, we create household-level instruments indicating whether a household member is a noncitizen and lives in a state with full or partial eligibility for noncitizens. $^{16}$

Workers can receive Temporary Disability Insurance benefits either through their employer or through the state if it has a TDI program and they have worked in covered employment. Domestic and family workers are generally not covered. California covers self-employed workers and Hawaii covers state and local government employees. Agricultural workers are covered in three states: California, Hawaii, and New Jersey. We interact state-level coverage with industry codes of last employment to create a variable measuring whether an individual is covered by a state-administered TDI program as an instrument for TDI participation.

\section{Results}

We begin the empirical analysis with summary statistics for non-employment spells as shown in table 2. The average spell duration is 6.86 months and seven out of 10 spells end with re-employment. Another 0.74 percent and 0.84 of all spells end with an application for DI and SSI, respectively. The remaining spells are right-censored.

\footnotetext{
${ }^{16}$ The SNAP Rules Database currently covers the years 1996 to 2007. Since states have not changed their noncitizen eligibility rules and biometric technology since the early 2000s, we assume that rules remain the same between 2007 and 2010. We also assume zero outreach spending for 2008 to 2010 (because of lack of information), which effectively is an assumption that any outreach spending in 2008 to 2010 had no effect on participation.
} 
The two largest temporary assistance programs are UI (16.15 percent of all non-employed workers receive UI benefits) and SNAP (16.56 percent). Participation in TDI and TANF is much lower, namely 0.53 percent and 3.39 percent, respectively. Most TANF recipients (over 90 percent in the sample) also receive SNAP. In terms of benefits, UI and TDI are by far the most generous programs with an average monthly benefit amount of 738.54 and 1015.38 dollars, respectively. TANF and SNAP benefits are by contrast relatively modest, averaging 126.74 and 264.02 dollars respectively.

Figure 1 shows how participation in these programs evolves over the course of nonemployment spells. The four months preceding a job separation are shown as well. UI is the program most targeted at job loss events and designed to provide short-term benefits. UI participation jumps up at the first month of non-employment, increases further to reach about 15 percent during the third and seventh month, and then declines steadily. The other programs show a more moderate increase at the beginning of non-employment, followed by a constant or slightly increasing participation rate. One should note, however, that these patterns are confounded by differential attrition rates for individuals who are on a program versus individuals who are not. For instance, some of the increase in SNAP participation rates can be explained by longer non-employment spell duration for those on the program.

Table 3 depicts first-stage results for IV regressions using individual person-months as the unit of observation. All regressions use clustered standard errors at the state level. The table also shows F-statistics for the test of the null that the coefficients on all "relevant" instruments for a temporary assistance program are zero (i.e. the excluded instruments have no impact on participation) as well as for the test that all instruments’ coefficients are zero. Relevant instruments for one temporary assistance program are those instruments deemed on a priori theoretical grounds to influence participation in that particular program.

UI participation is higher in states and years where the UI maximum benefit amount is higher. The other instruments for UI participation are not statistically significant, with the exception of the alternative base period, which is related to a lower participation rate. It might be the case that states with a lower UI participation rate are more prone to implement the alternative base period to boost participation rates, which could explain the negative coefficient. Also puzzling is the positive coefficient for TANF benefits at zero earnings and the negative coefficient for SNAP biometric information. The latter might indicate that states with a biometric 
system are also more restrictive about UI. Similarly, higher TANF benefits at zero earnings are correlated with higher UI maximum benefits $(\rho=0.35)$, suggesting that these TANF benefits proxy aspects of generosity or accessibility of the UI programs not accounted for otherwise.

For TDI, workers residing in states with a state program are more likely to receive temporary disability benefits, as one would expect if the state program did not completely crowd out private coverage. For TANF, benefits at zero earnings predict participation rates as expected. For both programs, however, some theoretically irrelevant instruments are significant as well. For SNAP, outreach spending per person and partial eligibility for noncitizens predict SNAP participation. In addition, TANF benefits and TDI coverage are inversely related to participation, but states with UI benefits extensions beyond 26 weeks for those on training programs tend to have higher participation rates. The negative coefficient for TANF on SNAP participation could indicate a substitution effect; the other irrelevant instruments apparently proxy state-level characteristics, but it is not clear which ones.

To summarize, relevant instruments tend to have the expected sign and are significant, but instruments from other programs are also correlated with program participation. As a result, the F-tests for the instruments are relatively strong when all instruments are considered, but modest to weak for "relevant" instruments alone. This discrepancy indicates that other factors on the state level are correlated with take-up decisions. This poses two problems. First, it is less clear how to interpret IV estimates if they are based on workers whose temporary assistance participation decision is influenced by both relevant and irrelevant instruments. For instance, it is relatively clear which kind of individual is on SNAP because of higher outreach spending, but it is less clear which kind of individual would be swayed to take up SNAP benefits because of lower TANF benefits. Second, state characteristics could be correlated with applications for DI and SSI, violating the exclusion restriction. However, we take the view that the excluded instruments capture variation over time in the relative generosity of packages of state policy which in turn affect participation.

Table 4 presents regression results using individual-month as unit of observation. Columns 1 to 3 show OLS results for re-employment, DI application, and SSI application, respectively, and columns 4 to 6 show corresponding IV results. All regressions use demographic variables from the SIPP and state unemployment rates from the Bureau of Labor Statistics as controls. 
Starting with the OLS results, the first column shows that participation in any of the temporary assistance programs is negatively associated with re-employment. This negative association could signify that the negative substitution effect outweighs the positive income effect or that individuals who receive such benefits have other characteristics (such as worse health) that make it harder for them to find a job. While we include a dummy variable for work limitation in our regressions, it is conceivable that it does not fully capture all relevant dimensions of health. The next two columns show that the association between the different temporary assistance programs and applications for DI or SSI is less uniform. The negative coefficient for UI participation on DI and SSI applications could indicate that taking up UI deters people from applying for this program. Alternatively, it might indicate that people on UI tend to have stronger labor force attachment and higher past earnings, and for that reason are less likely to qualify for SSI based on their income and savings.

The estimate for TDI participation with respect to DI application is positive, but the corresponding estimate for SSI application is not significantly different from zero. The positive coefficient with respect to DI applications can result from a worse health status of TDI participants as compared to non-participants. However, the coefficient with respect to SSI application should then also be positive as well, which is not the case. One possible explanation is that workers who qualify for TDI tend to be high wage earners (similar to UI recipients) in better jobs that provide such benefits, and therefore likely to be ineligible for SSI. TANF participation is not positively or negatively associated with either DI or SSI, but SNAP participation is negatively related to applications for DI and positively to applications for SSI. Presumably, SNAP recipients are more likely to be poor or lack a steady work history, which qualifies them for SSI but not for DI.

The results without correcting for endogeneity already suggest that workers sort into different TA programs and DI or SSI based on their past labor force attachment and their health status. However, some of the OLS coefficients could also represent program participation effects. The next three columns present second stage results for the IV regressions in order to identify possible causal effects of participation in temporary assistance programs on reemployment and application for DI and SSI.

Looking first at re-employment, we can see that two coefficients are now positive and none of them is significant. The size of the coefficients and their standard errors tend to be very 
large, typical in instrumental variables estimation, though large standard errors may also indicate weak instruments or heterogeneity in outcomes. While it would be more desirable to have precisely estimated coefficients, these results still suggest that the negative association between program participation and re-employment is primarily due to selection. Therefore, the indirect effect of temporary assistance participation on applications for DI and SSI through reemployment seems to be of secondary importance for our evaluation. However, this result is somewhat at odds with studies which find that UI benefits increase unemployment duration.

Turning to the next column for DI applications, one can see that the coefficient on UI participation is negative and strongly significant, consistent with other studies which have looked at the interaction between the UI program and applications for DI (Lindner 2011, Rutledge 2011). Moreover, the coefficients for other temporary assistance programs, while not significant, are all now negative. Most notably, the OLS estimate for TDI participation was positive and significant, and the IV result is negative and insignificant. Overall, these results suggest that if participation in temporary assistance influences applications for DI, then they function as a substitute on average. I.e. though participation may act to both increase and decrease application rates, the net effect for those induced to participate by small increases in eligibility or generosity is to actually reduce applications, or at least to not increase them.

Results are more mixed for SSI, as shown in the last column. Two coefficients (TANF and SNAP) have a positive sign, while the other two (UI and TDI) have a negative sign. Only the coefficient for SNAP participation is significant. It is not immediately clear why we find a significant coefficient of SNAP participation on SSI, but not on DI. Both SSI and SNAP are means-tested programs, i.e., they target poor families with little income and assets. As a consequence, individuals who participate in SNAP are likely to be eligible for SSI as well. They are also like to be ineligible for DI for the same reason, since DI requires a recent and sufficient work history. In other words, the population targeted by SNAP and SSI is similar, but does not overlap much with the DI's target population. The same reasoning applied to UI can explain why we find a significant coefficient of UI participation on DI applications, but no discernible effect on SSI applications. Neither UI nor DI is means-tested, but both programs have earnings and employment requirements. Their target populations overlap somewhat, but UI recipients are much less likely to be eligible for SSI, which is means-tested. 
The negative effect of UI participation on applications for DI suggests that the substitution effect dominates the income effect, but the positive effect of SNAP participation on applications for SSI suggests the opposite. One possible explanation is that the income effect dominates for low benefit levels, whereas the substitution effect dominates for high benefit levels. Alternatively, the effect of receiving cash transfers could depend on the group receiving them. While UI beneficiaries with their strong labor force attachment may be more easily dissuaded from applying for DI, low-income job losers with functional limitations who receive SNAP might see their benefits as a step towards receiving SSI benefits or may learn by receiving benefits while not employed that they can survive on less income and no job.

The different results could also indicate institutional complementarities or lack thereof. $\mathrm{UI}$ is a program for able and available workers, and recipients might therefore be reluctant to apply for DI even if they are eligible. For SNAP, parents with children on SNAP and SSI could find it easier to claim benefits for both programs, or SNAP case workers might direct people who qualify for SNAP to the SSI office since both programs have similar eligibility rules.

So far, the discussion has focused on months as unit of observation. Concerning spells as unit of observation, Table 5 presents the corresponding results. All of the coefficients have the same signs, but the standard errors tend to be larger relative to their coefficients as compared to table 4. Therefore, coefficients are generally less precisely estimated, and the coefficient for instrumented SNAP participation on applications for SSI is not significant. This result casts some doubt regarding the positive effect of SNAP participation on SSI applications as found for months as unit of observation. The higher sample size for months as units of observation as compared to spells as unit of observation might contribute to this difference. Clustering at the state level, however, accounts for correlated errors at the individual level and reduces the effective sample size appropriately.

For spells as unit of observation, the results can be directly translated into a quantitative interpretation. Recall from Table 2 that 0.74 percent of all spells end in an application for DI and another 0.87 percent in an application for SSI. The mean spell values are therefore 0.0074 and 0.0087 for DI and SSI applications, respectively. The IV estimate for the effect of UI participation on DI application in table 5 is -.0384 , or about 5 times as large as fraction of spells ending with an application for DI. The quantitative interpretation is similar for months as unit of observation. Here, 0.0074 DI applications per spell translate into about 0.001 applications per 
month (since the average spell duration is 6.86 months), and the coefficient for UI participation is about 6 times larger. Similarly, the effect of SNAP participation on applications for SSI is about 5 times the average number of applications for SSI per month. Overall, participation in temporary assistance programs seems to be able to influence application decisions for a large number of potential applicants for both DI and SSI.

\section{Conclusion}

This paper addresses whether and how participation in temporary assistance programs influence re-employment and applications for DI and SSI. We focus on workers who have lost their job because temporary assistance payments are an important income supports for them and because they are more likely to apply for DI and SSI than employed workers. After correcting for selection bias by instrumenting for temporary assistance participation using state policies and rules, we find evidence that temporary assistance programs may be substitutes or complements for DI and SSI application. On the one hand, UI participation appears to deter applications for DI. On the other hand, claiming SNAP benefits may increase applications for SSI, though evidence is mixed (the apparent effect is only statistically significant in the estimates using person-months as the unit of observation, analogous to a hazard model).

These results provide an overview of the interaction between temporary assistance programs and applications for DI and SSI. Three main conclusions can be drawn. First, applications for DI and SSI are sensitive to participation in temporary assistance programs. For re-employment, we do not find a systematic effect, but both coefficients and standard errors tend to be large for this outcome. Second, the size of the temporary assistance programs and their overlap with DI and SSI seems to matter. We only found significant effects for UI and SNAP, which are the two largest programs considered here. The target population for UI overlaps with the one for DI, but not with SSI as a means-tested program. Conversely, SNAP and SSI are both means-tested programs, but because these people tend to be poor and have a weak labor force attachment, they often do not qualify for DI benefits. Third, we find a negative effect of UI participation on DI, but (sometimes) a positive effect of SNAP participation on SSI. There are different explanations that can reconcile the opposite signs. For instance, the effect of receiving temporary assistance on applications for DI and SSI could vary by benefit level. It is not implausible that low benefit amounts (as provided by SNAP) without a fixed time limit primarily support applications, and 
only high benefit amounts (as provided by UI) with a fixed time limit deter applications. Other explanations are that program effects depend on the population involved (with greater or less intrinsic attachment to the labor force) or on other characteristics of temporary assistance programs.

Which of these explanations contributes to the observed findings remains unclear. Similarly, we cannot distinguish in some cases between no program effect and an imprecisely measured program effect. Most prominently, all the IV estimates for re-employment are large but insignificant. This result could mean that there is no systematic re-employment effect, or that our instruments do not allow us to estimate it in a precise way. By focusing on specific aspects of the interaction between temporary assistance programs and applications for DI and SSI, future research may be able to provide clearer answers to these questions. 


\section{References}

Autor, David H., and Mark G. Duggan. "The Growth in the Social Security Disability Rolls: A Fiscal Crisis Unfolding." Journal of Economic Perspectives 20 (2006): 71-96.

Black, Dan, Kermit Daniel, and Seth Sanders. "The Impact of Economic Conditions on Participation in Disability Programs: Evidence from the Coal Boom and Bust." American Economic Review 92, no. 1 (2002): 27-50.

Bound, John, and Richard V. Burkhauser. Economic Analysis of Transfer Programs Targeted on People with Disabilities. In Handbook of Labor Economics, edited by Orley Ashenfelter and David Card, 3417-3528. Elsevier, 1999.

Bound, John, Richard J. Burkhauser, and Austin Nichols. "Tracking the Household Income of SSDI and SSI Applicants." In Worker Well-being and Public Policy, edited by Solomon W. Polachek, 113-148. Amsterdam: JAI, 2003.

Card, David, Raj Chetty, and Andrea Weber. "Cash-on-Hand and Competing Models of Intertemporal Behavior: New Evidence from the Labor Market." Quarterly Journal Economics 122, no. 4 (2007): 1511-1560.

Chetty, Raj. "Moral Hazard versus Liquidity and Optimal Unemployment Insurance." Journal of Political Economy 116 (2008): 173-234.

Finegold, Kenneth, William Margrabe, and Caroline Ratcliffe. "SNAP Program Rules Database Documentation." Washington, DC: The Urban Institute, 2010.

Imbens, Guido W., and Joshua D. Angrist. "Identification and Estimation of Local Average Treatment Effect." Econometrica 62 (1994): 467-475.

Lindner, Stephan. "How Does Unemployment Insurance Affect the Decision to Apply for Social Security Disability Insurance?" The University of Michigan, 2011.

Meyer, Bruce D. "Unemployment Insurance and Unemployment Spells." Econometrica 58, no. 4 (1990): 757-782.

Ratcliffe, Caroline, and Signe-Mary McKernan. "How Much Does SNAP Reduce Food Insecurity?" Washington, DC: The Urban Institute, 2010. 
Rowe, Gretchen, Mary Murphy, and Ei Yin Mon. "Welfare Rules Databook." Washington, DC: The Urban Institute, 2010.

Rupp, Kalman, and David Stapleton. "Determinants of the Growth in the Social Security Administration's Disability Programs -- An Overview." Social Security Bulletin 58, no. 4 (1995): 43-70.

Rutledge, Matthew. "The Impact of Unemployment Benefits Extensions on Disability Insurance Application and Allowance Rates." CRR Working Paper No. 2011-17. Chestnut Hill, MA: Center for Retirement Research at Boston College, 2011.

Social Security Administration. "Social Security Programs in the United States." Washington, DC, 1997.

Staiger, Douglas, and James H. Stock. "Instrumental Variables Regression with Weak Instruments." Econometrica 65 (1997): 557-586.

U.S. Committee on Ways and Means. "Green Book." Washington, DC, 1996.

U.S. Committee on Ways and Means. "Green Book." Washington, DC, 2000.

U.S. Committee on Ways and Means. "Green Book." Washington, DC, 2004.

Young, Cristobal. "Unemployed Workers and Job Search Effort: Evidence from Random Audits." Stanford University, 2011. 


\section{Appendix}

\section{A Description of Selected Instruments}

\section{UI program variables:}

Alternative base period: Historically, the base period has been used to assess monetary eligibility of UI claimants. The base period includes the first four of the last five completed calendar quarters. The base period therefore ignores up to six months of earnings prior to the date a claim is filed. For instance, if a worker claims benefits June $20^{\text {th }} 2011$, then the last completed quarter is January to March 2010, and the base period includes January to December 2010. The alternative base period (ABP) reduces the gap between the quarters counted for monetary eligibility and the time a claim is filed by including the last four completed quarters to determine monetary eligibility. In some states, the alternative base period includes the last three completed quarters before filing a claim, plus the current quarter.

Wages in two quarters: UI claimants are only monetary eligible if they have earned wages in two of the four quarters under consideration (either base period or alternative base period). Waiting week: UI claimants do not receive benefit during the first week of eligibility in such states.

Dependency allowance: UI claimants may receive additional benefits for dependent family members. In order to receive ARRA funds, states are required to pay at least \$15 per dependent up to $\$ 50$ per week.

Domestic violence / moving with spouse / filial obligations: These are good-cause provisions for non-monetary eligibility, i.e., workers may quit employment for one of these reasons and still be eligible for UI. Filial obligations include taking care of ill or disabled immediate family member. These provisions are part of the ARRA.

Part-time work: Workers who only seek part-time work are still eligible for UI benefits. This provision is part of the ARRA.

26 weeks: UI benefits continue for at least 26 additional weeks after exhaustion of regular benefits while the UI claimant is in approved training. This provision is part of the ARRA. 


\section{TDI program variables:}

Covered by state TDI insurance: Five states currently offer temporary disability insurance: California, Hawaii, New Jersey, New York, and Rhode Island. These states cover different groups of workers. California is the only state to include the self-employed, while Hawaii is the only state to cover local government workers. Agricultural workers are covered in California, Hawaii, and New Jersey. We use industry codes of the last job to identify whether a worker is covered in one of these states.

\section{TANF program variables:}

Imputed TANF benefits at zero earnings: We use state benefit formulas to determine for each state and year TANF benefits of families with zero earnings.

\section{SNAP program variables:}

Biometric technology used: Some states have introduced biometric technology (typically fingerprints) to verify an applicant's identity and thereby reduce multiple participation fraud. As of 2010, five states have such a policy in place: Arizona, California, Massachusetts, New York, and Texas.

Outreach spending per person: Amount of federal and nonfederal outlays as well as outreach grants per non-SNAP participants with a household income below 150 percent of the federal poverty threshold in as state.

Noncitizen fully eligible x noncitizen in household: Equals to one for a household if noncitizens are fully eligible for SNAP benefits in a state and at least one noncitizen lives in that household. Noncitizen were fully eligible for SNAP benefits prior to the 1996 welfare reform, but lost eligibility with the reform. After the welfare reform, some states introduced legislation to restore full eligibility for noncitizens. These changes occurred between 1997 and 2003, and since then, six states have restored full eligibility for noncitizens. These are California, Connecticut, Maine, Nebraska, Washington, and Wisconsin.

Noncitizen partly eligible x noncitizen in household: Equals to one for a household if noncitizens are eligible for SNAP benefits in a state under certain circumstances and at least one noncitizen lives in that household. Noncitizen were fully eligible for SNAP benefits prior to the 1996 welfare reform, but lost eligibility with the reform. Some states restore partial eligibility after the 
welfare reform, and the Farm Security and Rural Investment Act of 2002 restored eligibility for noncitizens if they have a disability, if they have been U.S. residents for at least 5 years, or if they are children under 18 years. 
Figure 1: PARTicipation in TA PRograms By SPELl DURATion

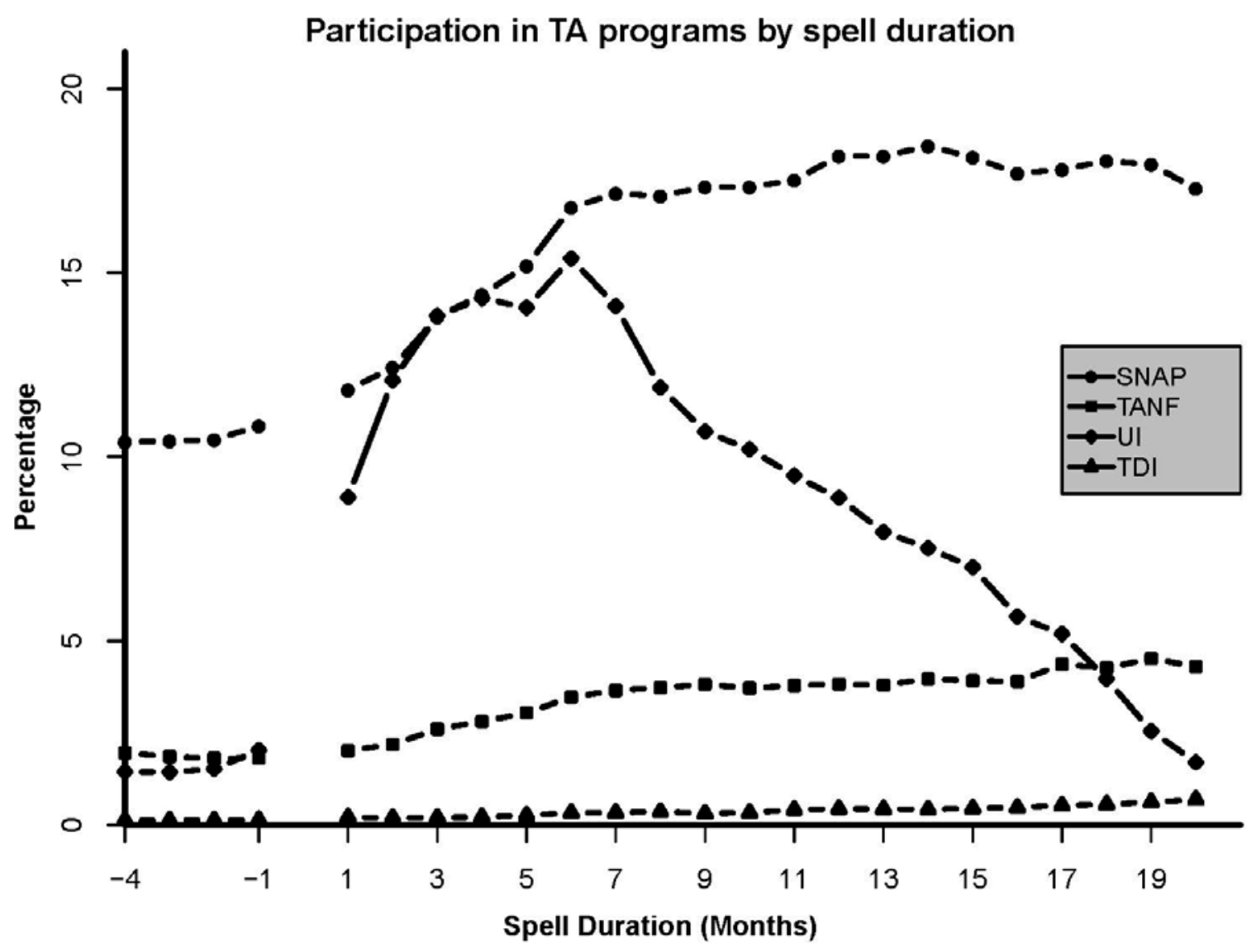

Notes: Negative spell duration is for months prior to spells of non-employment. 
Table 1: SAMple Selection and SAMPle Size

\begin{tabular}{lr}
\multicolumn{1}{c}{ Selection steps } & Sample size \\
\hline Universe & 469565 \\
Complete interview & 393900 \\
SSN disclosure & 291676 \\
Non-employment spell & 201323 \\
Age 20-57 at first month of spell & 68926 \\
Employment history > 3 months & 40741 \\
No layoffs & 34867 \\
Complete spell & 32829 \\
State identified & 32613 \\
No prior DI/SSI application & 32208 \\
\hline
\end{tabular}

Notes: Sample sizes displayed are unweighted number of individuals. Each row shows the number of individuals who meet the respective requirements. See text for details of the selection steps. 
TABLE 2: SumMARY StATISTICS

\begin{tabular}{|c|c|c|c|c|}
\hline Variable & $\begin{array}{c}\text { Mean / } \\
\text { Percentag } \\
\text { e }\end{array}$ & $\begin{array}{c}25^{\text {th }} \\
\text { Percentil } \\
\text { e }\end{array}$ & Median & $\begin{array}{c}75^{\text {th }} \\
\text { Percentil } \\
\text { e }\end{array}$ \\
\hline Age & 35.25 & 25 & 34 & 44 \\
\hline Male & 42.11 & 0 & 0 & 100 \\
\hline White & 80.9 & 100 & 100 & 100 \\
\hline Married & 49.91 & 0 & 0 & 100 \\
\hline High-school degree & 89.93 & 100 & 100 & 100 \\
\hline Some college & 60.09 & 0 & 100 & 100 \\
\hline Noncitizen immigrant in household & 11.77 & 0 & 0 & 0 \\
\hline Number of children $<18$ & 0.95 & 0 & 0 & 2 \\
\hline Medicaid coverage during month & 10.16 & 0 & 0 & 0 \\
\hline Private health insurance during month & 58.63 & 0 & 100 & 100 \\
\hline $\begin{array}{l}\text { Monthly earnings last year (moving } \\
\text { average) }\end{array}$ & 1621.43 & 496.53 & 1111.89 & 2081.5 \\
\hline Work Limitation & 11.25 & 0 & 0 & 0 \\
\hline Work limitation during panel & 23.47 & 0 & 0 & 0 \\
\hline Reason not working: health problem & 6.38 & 0 & 0 & 0 \\
\hline Number of spells of person & 1.31 & 1 & 1 & 1 \\
\hline Spell duration (in months) & 6.86 & 3 & 5 & 8 \\
\hline Exit: Employment (spell) & 70.67 & 0 & 100 & 100 \\
\hline Exit: DI (spell) & 0.74 & 0 & 0 & 0 \\
\hline Exit: DI/SSI or SSI (spell) & 0.87 & 0 & 0 & 0 \\
\hline Application for DI or SSI observed (person) & 1.74 & 0 & 0 & 0 \\
\hline Unemployment (percentage by state/month) & 5.67 & 4.4 & 5.2 & 6.3 \\
\hline UI recipient during spell & 16.15 & 0 & 0 & 0 \\
\hline UI benefit amount & 738.54 & 353.51 & 636.86 & 1003.76 \\
\hline TDI recipient during spell & 0.53 & 0 & 0 & 0 \\
\hline TDI benefit amount & 1015.38 & 420 & 854 & 1384 \\
\hline TANF/AFDC: Fam. recipiency (spell) & 3.39 & 0 & 0 & 0 \\
\hline TANF/AFDC: Fam. amount & 126.74 & 60.64 & 100.45 & 160.81 \\
\hline SNAP: Household recipiency (spell) & 16.56 & 0 & 0 & 0 \\
\hline SNAP: Household amount & 264.02 & 132.47 & 236.06 & 346.64 \\
\hline UI: Wages in two quarters & 24.17 & 0 & 0 & 0 \\
\hline UI: Waiting week & 81.32 & 100 & 100 & 100 \\
\hline UI: Alternative base period & 29.81 & 0 & 0 & 100 \\
\hline UI: Dependency Allowance & 25.29 & 0 & 0 & 100 \\
\hline
\end{tabular}




\begin{tabular}{|c|c|c|c|c|}
\hline Variable & $\begin{array}{c}\text { Mean / } \\
\text { Percentag } \\
\text { e }\end{array}$ & $\begin{array}{c}25^{\text {th }} \\
\text { Percentil } \\
\text { e }\end{array}$ & Median & $\begin{array}{c}75^{\text {th }} \\
\text { Percentil } \\
\text { e }\end{array}$ \\
\hline UI: Domestic Violence & 48.07 & 0 & 0 & 100 \\
\hline UI: Move with Spouse & 25.01 & 0 & 0 & 100 \\
\hline UI: Filial Obligations & 39.11 & 0 & 0 & 100 \\
\hline UI: Part-time work & 37.34 & 0 & 0 & 100 \\
\hline UI: 26 weeks & 15.13 & 0 & 0 & 0 \\
\hline UI: Maximum weekly benefit amount & 301.6 & 253.91 & 291.39 & 345.03 \\
\hline Covered by state TDI insurance & 11.77 & 0 & 0 & 0 \\
\hline Imputed TANF benefit at zero earnings & 376.48 & 255.06 & 349.25 & 485.37 \\
\hline SNAP: Biometric technology used & 20.29 & 0 & 0 & 0 \\
\hline SNAP: Outreach spending per person & 0.02 & 0 & 0 & 0 \\
\hline $\begin{array}{l}\text { SNAP: Noncitizen fully eligible } \mathrm{x} \\
\text { noncitizen in household }\end{array}$ & 3.64 & 0 & 0 & 0 \\
\hline $\begin{array}{l}\text { SNAP: Noncitizen partly eligible } \mathrm{x} \\
\text { noncitizen in household }\end{array}$ & 7.51 & 0 & 0 & 0 \\
\hline
\end{tabular}

Notes: Fractions are shown as percentages. Dollar amounts are in January 200 values. Monthly observations are used if not otherwise stated. The first month of non-employment spells is used for age, male, white, married, high-school degree and some college. Temporary assistance participation refers to whole spell. For a description of the instrumental variables, see appendix A. 
TABle 3: First-STAge Results (FUll SAMPle, INDiVIDUAL-MONTH AS UNiT OF ObSERVATION)

\section{Instrument}

UI: Maximum weekly benefit amount

UI: Waiting week

UI: Wages in two quarters

UI: Alternative base period

UI: Dependency Allowance

UI: Domestic Violence

UI: Move with Spouse

UI: Filial Obligations

UI: Part-time work

UI: 26 weeks

TDI: Covered by state TDI insurance

TANF: Imputed benefits at zero earnings

SNAP: Biometric technology used

SNAP: Outreach spending per person

\section{UI partic.}

$0.2511^{* *}$

(0.0711)

0.0029

(0.0118)

$-0.0082$

(0.0094)

$-0.0171 *$

(0.0069)

0.017

$(0.0090)$

0.0041

(0.0079)

$-0.063$

(0.0103)

$-0.0035$

(0.0063)

$-0.0032$

(0.0091)

0.0145

(0.0129)

$-0.0248$

(0.0176)

$0.1327 * *$

(0.0486)

$-0.0201^{* *}$

(0.0074)

$-0.0421$
TDI partic.

$-0.0109$

(0.0163)

0.0015

(0.0028)

$-0.0007$

(0.0017)

0.0033

(0.0019)

0.0024

(0.0023)

0.0035

(0.0024)

0.0029

(0.0023)

$-0.0014$

(0.0019)

$-0.0018$

(0.0022)

$-0.0021$

(0.0021)

$0.0090 * *$

(0.0026)

$-0.0015$

(0.0082)

0.0003

(0.0021)

0.0040
TANF partic. SNAP partic.

0.0386

(0.0366)

$-0.1413$

(0.0860)

0.0007

0.0172

$(0.0053)$

0.0036

(0.0061)

$-0.0043$

(0.0054)

0.0093

(0.0063)

0.0071

$(0.0068)$

0.0058

$(0.0062)$

$-0.0120 *$

$(0.0051)$

$-0.0014$

(0.0059)

$-0.0036$

(0.0068)

0.0163*

(0.0074)

$0.0437 *$

(0.0174)

0.0000

(0.0057)

0.0140
(0.0129)

$-0.0058$

(0.0115)

$-0.0081$

(0.0079)

$-0.0059$

(0.0114)

0.0061

(0.0086)

$-0.0046$

(0.0101)

$-0.0037$

(0.0092)

$-0.0087$

(0.0078)

$0.0267 *$

(0.0121)

$-0.0368 * *$

(0.0097)

$-0.1550 * * *$

(0.0336)

$-0.0144$

(0.0104)

$0.0443 *$ 
SNAP: Immigrants fully eligible

SNAP: Immigrants partially eligible

SNAP: Noncitizen fully eligible x noncitizen in household

SNAP: Noncitizen partly eligible x noncitizen in household

F-Test for relevant instruments

F-Test for all instruments

$\begin{array}{rrrr}(0.0210) & (0.0053) & (0.0085) & (0.0174) \\ 0.0274 * & 0.0092^{*} & -0.0072 & 0.0087 \\ (0.0121) & (0.0043) & (0.0085) & (0.0141) \\ 0.0002 & 0.0039 * & 0.0017 & -0.0022 \\ (0.0054) & (0.0017) & (0.0054) & (0.0069) \\ 0.0385 & -0.0185 * & -0.0045 & -0.0058 \\ (0.0225) & (0.0080) & (0.0163) & (0.0206) \\ -0.0132 & -0.0110 & -0.0002 & 0.0433^{*} \\ (0.0215) & (0.0069) & (0.0152) & (0.0170)\end{array}$

5.68

11.54

16.29

6.33

9.62

4.86 26.99

Notes: Standard errors are in parentheses. Standard errors are clustered on the state level. All specifications include demographic variables. Temporary assistance participation refers to spell. F-statistics test for the null hypothesis that all estimates equal to zero, where relevant instruments refers to instruments relevant for a respective TA (e.g., all UI instruments for UI participation) and all instruments refers to all instruments displayed in the table. For a description of the instrumental variables, see appendix A.

* $\quad$ Significantly different from zero at the 5 percent confidence level.

** Significantly different from zero at the 1 percent confidence level.

*** Significantly different from zero at the 0.1 percent confidence level. 
TABLE 4: REgRESSION RESUlts, INDIVIDUAL-MONTH AS UNit OF OBSERVATION

\begin{tabular}{|c|c|c|c|c|c|c|}
\hline & \multicolumn{3}{|c|}{ OLS } & \multicolumn{3}{|c|}{ IV } \\
\hline & Employment & DI & SSI & Employment & DI & SSI \\
\hline \multirow[t]{2}{*}{ UI recipient } & $-0.0314 * * *$ & 0.0000 & $-0.0005^{* * *}$ & 0.2813 & $-0.0061 * * *$ & -0.0045 \\
\hline & $(0.0021)$ & $(0.0001)$ & $(0.0001)$ & $(0.1795)$ & $(0.0017)$ & $(0.0035)$ \\
\hline \multirow[t]{2}{*}{ TDI recipient } & $-0.0338 * * *$ & $0.0107 * * *$ & 0.0003 & -1.4674 & -0.0253 & -0.0122 \\
\hline & $(0.0048)$ & $(0.0024)$ & $(0.0015)$ & (1.0369) & $(0.0242)$ & $(0.0196)$ \\
\hline \multirow[t]{2}{*}{ TANF/AFDC recipient } & $-0.0130 * * *$ & 0.0002 & 0.0005 & -0.5386 & -0.0020 & 0.0110 \\
\hline & $(0.0024)$ & $(0.0002)$ & $(0.0005)$ & $(0.5361)$ & $(0.0074)$ & $(0.0095)$ \\
\hline \multirow[t]{2}{*}{ SNAP recipient } & $-0.0170 * * *$ & $-0.0006 * *$ & $0.0008 * * *$ & 0.0699 & -0.0057 & $0.0056 * *$ \\
\hline & $(0.0025)$ & $(0.0002)$ & $(0.0004)$ & $(0.1610)$ & $(0.0031)$ & $(0.0021)$ \\
\hline \multicolumn{5}{|l|}{ F-statistic } & 3.319 & \\
\hline
\end{tabular}

Notes: Standard errors are in parentheses. Standard errors are clustered on the state level. All specifications include demographic variables. The F-statistic is the Kleibergen-Paap F-statistic. See text for details.

* $\quad$ Significantly different from zero at the 5 percent confidence level.

** Significantly different from zero at the 1 percent confidence level.

*** Significantly different from zero at the 0.1 percent confidence level. 
TABle 5: Regression ReSUlts, INDIVIDUAL-SPELl AS UNIT OF OBSERVATION

\begin{tabular}{|c|c|c|c|c|c|c|}
\hline & \multicolumn{3}{|c|}{ OLS } & \multicolumn{3}{|c|}{ IV } \\
\hline & Employment & DI & SSI & Employment & DI & SSI \\
\hline \multirow[t]{2}{*}{ UI recipient } & $-0.0234 * *$ & 0.0003 & $-0.0032 * *$ & 0.2160 & $-0.0384 * * *$ & -0.0307 \\
\hline & $(0.0081)$ & $(0.0008)$ & $(0.0010)$ & $(0.1284)$ & $(0.0113)$ & $(0.0228)$ \\
\hline \multirow[t]{2}{*}{ TDI recipient } & $-0.2459 * * *$ & $0.1408 * * *$ & 0.0247 & -1.5535 & 0.0077 & -0.1335 \\
\hline & $(0.0376)$ & $(0.0245)$ & $(0.0170)$ & $(1.3657)$ & $(0.2630)$ & $(0.2445)$ \\
\hline \multirow[t]{2}{*}{ TANF/AFDC recipient } & $-0.0481 * *$ & 0.0002 & 0.0095 & 0.1231 & -0.0414 & 0.0212 \\
\hline & $(0.0147)$ & $(0.0015)$ & $(0.0053)$ & $(0.4450)$ & $(0.0656)$ & $(0.0773)$ \\
\hline \multirow[t]{2}{*}{ SNAP recipient } & $-0.0407 * * *$ & -0.0015 & $0.0139 * * *$ & 0.2002 & -0.0332 & 0.0232 \\
\hline & $(0.0106)$ & $(0.0013)$ & $(0.0025)$ & $(0.1976)$ & $(0.0236)$ & $(0.0260)$ \\
\hline \multicolumn{5}{|l|}{ F-statistic } & 2.476 & \\
\hline
\end{tabular}

Notes: Standard errors are in parentheses. Standard errors are clustered on the state level. All specifications include demographic variables.

* $\quad$ Significantly different from zero at the 5 percent confidence level.

** Significantly different from zero at the 1 percent confidence level.

*** $\quad$ Significantly different from zero at the 0.1 percent confidence level. 
RECENT WORKING PAPERS FROM THE

CENTER FOR RETIREMENT RESEARCH AT BOSTON COLLEGE

Understanding the Growth in Federal Disability Programs: Who Are the Marginal Beneficiaries, and How Much Do They Cost?

Adele Kirk, January 2012

What Explains State Variation in SSDI Application Rates?

Norma B. Coe, Kelly Haverstick, Alicia H. Munnell, Anthony Webb, December 2011

How Do Subjective Mortality Beliefs Affect the Value of Social Security and the Optimal Claiming Age?

Wei Sun and Anthony Webb, November 2011

How Does the Personal Income Tax Affect the Progressivity of OASI Benefits?

Norma B. Coe, Zhenya Karamcheva, Richard Kopcke, Alicia H. Munnell, November 2011

The Pension Protection Act of 2006 and Diversification of Employer Stock in Defined Contribution Plans

Gary V. Engelhardt, November 2011

Prescription Drug Insurance Coverage, Drug Utilization, and Cost-Related NonAdherence: Evidence from the Medicare Part D Expansion

Gary V. Engelhardt, November 2011

Social Security on Auto-Pilot: International Experience with Automatic Stabilizer Mechanisms

Barry Bosworth and R. Kent Weaver, November 2011

The Impact of Unemployment Insurance Extensions on Disability Insurance Application and Allowance Rates

Matthew S. Rutledge, October 2011

Do Couples Self-Insure? The Effect of Informal Care on a Couple's Labor Supply

Norma B. Coe, Meghan Skira, and Courtney Harold Van Houtven, October 2011

How Prepared are State and Local Workers for Retirement?

Alicia H. Munnell, Jean-Pierre Aubry, Josh Hurwitz, and Laura Quinby, October 2011

All working papers are available on the Center for Retirement Research website (http://crr.bc.edu) and can be requested by e-mail (crr@bc.edu) or phone (617-552-1762). 